\title{
Anatomia da raiz de espécies de Dyckia Schult. f. e Encholirium Mart. ex Schult. \& Schult. f. (Bromeliaceae, Pitcairnioideae) da Serra do Cipó (Minas Gerais, Brasil), com especial referência ao velame ${ }^{1}$
}

\author{
PATRÍCIA B. PITA ${ }^{2,3}$ e NANUZA L. MENEZES ${ }^{2}$
}

(recebido: 9 de agosto de 2000; aceito: 24 de outubro de 2001)

\begin{abstract}
Root anatomy in species of Dyckia Schult. f. and Encholirium Mart. ex Schult. \& Schult. f. (Bromeliaceae, Pitcairnioideae) from Serra do Cipó (Minas Gerais, Brazil), with special emphasis to velamen). An anatomical study of roots in species of Dyckia and Encholirium demonstrates as principal feature the presence of several layered epidermis that forms a velamen. The epivelamen has root hairs. The hypodermis has thickened walled, non living cells and some non thickened walled and living passage cells. It is one or several layred in different levels and entirely lignified. It's also observed that the other zones of the cortex are more or less thickened, depending on the level (thicker when next to the stem). The roots examined were adventiceous, with a pith, except the tap root of the young plant.

RESUMO - (Anatomia da raiz de espécies de Dyckia Schult. f. e Encholirium Mart. ex Schult. \& Schult. f. (Bromeliaceae, Pitcairnioideae) da Serra do Cipó (Minas Gerais, Brasil), com especial referência ao velame). O estudo anatômico da raiz em espécies de Dyckia e Encholirium mostra, como característica marcante, a presença de uma epiderme pluriestratificada, constituindo um velame. No epivelame, encontram-se os pêlos radiculares. A hipoderme é formada por células mortas de paredes espessadas e algumas células de passagem vivas de paredes não espessadas. Em diferentes níveis, apresenta-se uni ou plurisseriada e totalmente lignificada. Observa-se, também, o espessamento e a lignificação das paredes celulares de outras regiões do córtex em maior ou menor profundidade, dependendo do nível considerado (mais próximo do caule, mais espessado). Excluindo a raiz primária da planta jovem, todas as demais são adventícias, com medula ampla.
\end{abstract}

Key words - Bromeliaceae, root, anatomy, velamen

\section{Introdução}

A família Bromeliaceae é, predominantemente, Neotropical, com aproximadamente 2.000 espécies classificadas em três subfamílias: Pitcairnioideae, Bromelioideae e Tillandsioideae. (Cronquist 1981, Reitz 1983, Dahlgren et al. 1985). As Bromeliaceae são notáveis pela sua diversidade ecológica, apresentando espécies terrestres e epífitas, adaptadas aos ambientes mésicos, semimésicos e xéricos (Benzing et al. 1976).

Dentre os autores que estudaram os caracteres morfológicos, anatômicos e fisiológicos que adaptam as bromeliáceas aos diversos ambientes, citam-se Meyer (1940), Pittendrigh (1948), Tomlinson (1969), Benzing \& Dahle (1971), Gilmartin (1972), Benzing (1973), Smith \& Downs (1974), Benzing (1976), Benzing et al. (1978) e Benzing (1990).

Segundo Schimper (1888 apud Pittendrigh 1948), as epífitas dessa família evoluíram de espécies terrestres para as matas úmidas, e destas para o

1. Parte da dissertação de mestrado de Patrícia B. Pita.

2. Universidade de São Paulo, Instituto de Biociências, Departamento de Botânica, Caixa Postal 11461, São Paulo, SP.

3. Autor para correspondência: patpita@usp.br dossel, cuja atmosfera, servindo como fonte de água e nutrientes, permitiu que essas plantas se desligassem do solo. As adaptações que caracterizam tal evolução consistem na redução estrutural e funcional das raízes e na especialização dos tricomas foliares, as escamas, que podem suprir parcial ou totalmente a função de absorção das raízes (Gilmartin 1972, Benzing 1973, Benzing et al. 1978).

As espécies da subfamília Pitcairnioideae são terrestres, de natureza xerofítica, com um sistema radicular bastante desenvolvido, que desempenha as funções de absorção de água e sais minerais e de fixação da planta no substrato (Pittendrigh 1948). Suas folhas têm pouca ou nenhuma função de absorção. As outras subfamílias apresentam espécies terrestres e epífitas que ocupam ambientes mésicos a xéricos, com sistema radicular menos desenvolvido e que diminui, progressivamente, a função de absorção, concomitante com a evolução das escamas foliares como parte central na absorção de água e nutrientes (Pittendrigh 1948).

As espécies de Dyckia e Encholirium, estudadas neste trabalho, foram coletadas na Serra do Cipó, que ocupa uma posição intermediária em relação aos limites nordeste e sudeste de uma cadeia de montanhas conhecida como Cadeia do Espinhaço (Giulietti et al. 
1987). Dentre os tipos de vegetação que ocorrem na região, os campos rupestres constituem um tipo muito particular, com as plantas crescendo em solos arenosos de textura fina ou grossa ou sobre solos pedregosos decorrentes da desintegração das rochas, ou sobre a própria rocha (Joly 1970).

Este trabalho tem como objetivo fornecer informações a respeito das características anatômicas da raiz de Dyckia macedoi L.B. Smith, D. rariflora L.B. Smith, Encholirium heloisae (L.B. Smith) Forzza \& Wanderley e E. subsecundum (Bak.) Mez e as adaptações que as mesmas lhe confere para o ambiente em que vivem.

\section{Material e métodos}

O material foi coletado na Serra do Cipó, que está localizada entre os paralelos $19^{\circ} 17^{\prime \prime} \mathrm{S}$ e $43^{\circ} 30^{\prime \prime} \mathrm{W}$. A Cadeia do Espinhaço pode ser incluída no clima Cwb de Köppen (1931), clima mesotérmico com verões brandos e estação chuvosa no verão, cuja temperatura média varia de $17,4{ }^{\circ} \mathrm{C}$ a $19,8^{\circ} \mathrm{C}$.

Os espécimens estudados encontram-se depositados nos herbários SP e SPF, com os seguintes números de coletor: Dyckia macedoi L.B. Smith, R.C. Forzza 100; D. rariflora L.B. Smith, R.C. Forzza 101; Encholirium heloisae (L.B. Smith) Forzza \& Wanderley, R.C. Forzza 98, R.C. Forzza 139, R.C. Forzza 145; E. subsecundum (Bak.) Mez, R.C. Forzza 99, R.C. Forzza 104.

Foram colocadas sementes de E. subsecundum (R.C. Forzza 99) para germinar, com o objetivo de observar a estrutura das raízes de plantas jovens. As sementes foram colocadas em placas de Petri, com papel de filtro umedecido, periodicamente, com água destilada. As placas foram mantidas em estufa incubadora fotoperiódica da FANEM.

As raízes foram fixadas em FAA 50 (Johansen 1940) por $48 \mathrm{~h}$ e depois foram transferidas para etanol 50 GL. Foram feitos cortes à mão livre, com secções transversais dos terços apical, mediano e basal (próximo ao caule) das raízes, utilizando as técnicas usuais de Johansen (1940) e Sass (1951). O material obtido foi corado com azul de astra e fucsina básica segundo metodologia descrita por Kraus et al. (1998), montados entre lâmina e lamínula com glicerina $50 \%$ e lutadas com esmalte.

\section{Resultados}

Como as características anatômicas das raízes das espécies dos gêneros analisados são semelhantes, optou-se por ilustrar uma espécie de cada gênero, $D$. macedoi e E. heloisae, além de E. subsecundum, em que foi observada a estrutura da raiz jovem.

As espécies de Dyckia e Encholirium estudadas apresentam um sistema radicular funcional, com numerosas raízes adventícias, fortemente fixadas no substrato, no caso, em pedras.

A raiz, tanto nas espécies de Encholirium (figuras 1-5, 7-9 e 12) como de Dyckia (figuras 13-20), apresenta uma epiderme pluriestratificada, constituindo um velame, como se observa nas figuras 1-5, 7-9, 11-12 e 17-20. A região do epivelame apresenta pêlos radiculares observados nas figuras 1, 5, 7-8 e 12. Na região basal, o velame destaca-se da hipoderme, parcial ou totalmente, como se observa na figura 16 (setas).

A hipoderme, próximo ao ápice radicular, se apresenta como uma camada unisseriada (figuras 5-8), com células de paredes espessadas e lume bem reduzido e células de passagem com paredes primárias (figuras 7-8), que, em níveis mais próximos do caule, formam paredes secundárias. Na região basal da raiz, observase, também, uma progressiva esclerificação (de fora para dentro) das células do parênquima cortical (figuras 10-11, 13 e 16), que, nos níveis correspondentes às figuras 5-7, se apresenta com paredes celulares finas (apenas com parede primária) e, mais próximo do caule, se apresenta parcialmente lignificado (figura 16). No nível representado pela figura 6 , observa-se um maior espessamento de parede primária nas células da região mediana do córtex, constituindo um tecido colenquimatoso. Internamente à essa camada espessada (figura 6), verifica-se a presença de muitos espaços aéreos entre as células do córtex interno. Esses espaços podem ser observados também nas figuras 9-10 e 13-14. Essa região com espaços aéreos se mantém, mesmo quando o córtex se apresenta parcialmente lignificado (figura 16).

A endoderme, próximo ao ápice, apresenta-se com estrias de Caspary (figura 6); em níveis superiores ela se apresenta com espessamento nas paredes anticlinais, como observado nas figuras 9-10, com a presença de células de passagem (Cp) apenas com paredes primárias e estrias de Caspary. Nos níveis representados pelas figuras 13-16, não há células de passagem, por se situarem bem na base da raiz, região onde não ocorre absorção.

Essas raízes adventícias apresentam medula e observa-se, desde estágios precoces (figuras 5-6) até bem diferenciados (figuras 9-10 e 13-16), um parênquima medular totalmente lignificado. Quando se acompanha o deslocamento de uma raiz no córtex do caule (figura 17 - seta), verifica-se as divisões das células epidérmicas dessa raiz, que levam à formação do velame (figuras 17-20 - setas). Mesmo no nível em que a raiz se apresenta no interior do 

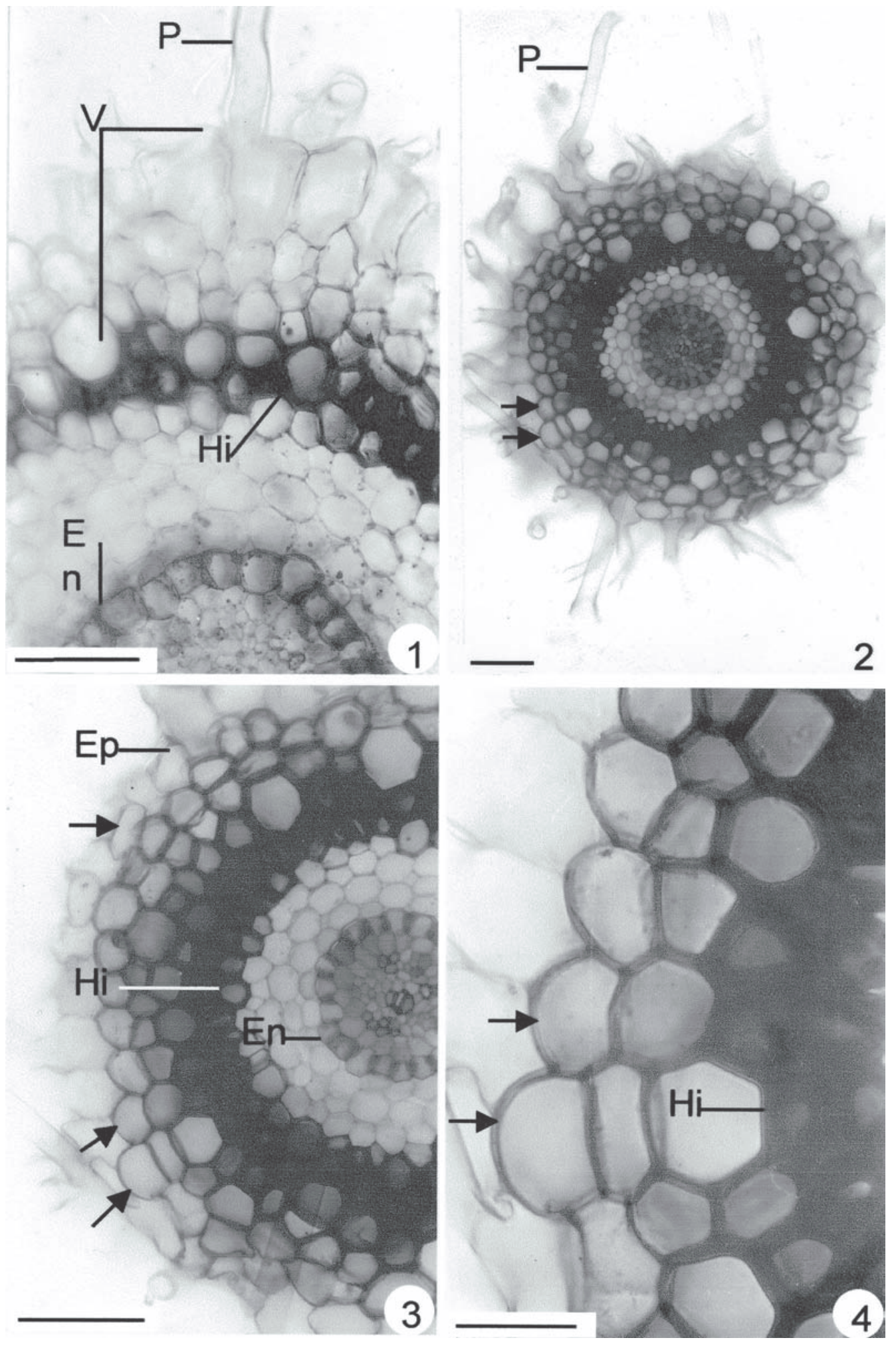

Figuras 1-4. Secções transversais em diferentes níveis de uma raiz primária de planta jovem de Encholirium subsecundum (R.C. Forzza 99). 1. Região mediana da raiz; 2-4. Região basal da raiz. As setas indicam a estratificação da epiderme. Observam-se os pêlos radiculares $(\mathrm{P})$ no epivelame $(\mathrm{EP})$. A endoderme $(\mathrm{En})$ já apresenta espessamento nas paredes anticlinais. Hi = hipoderme, $\mathrm{V}=$ velame. Escalas $=50 \mu \mathrm{m}$ (fig. 1); $100 \mu \mathrm{m}$ (fig. 2,3); $25 \mu \mathrm{m}$ (fig. 4). 

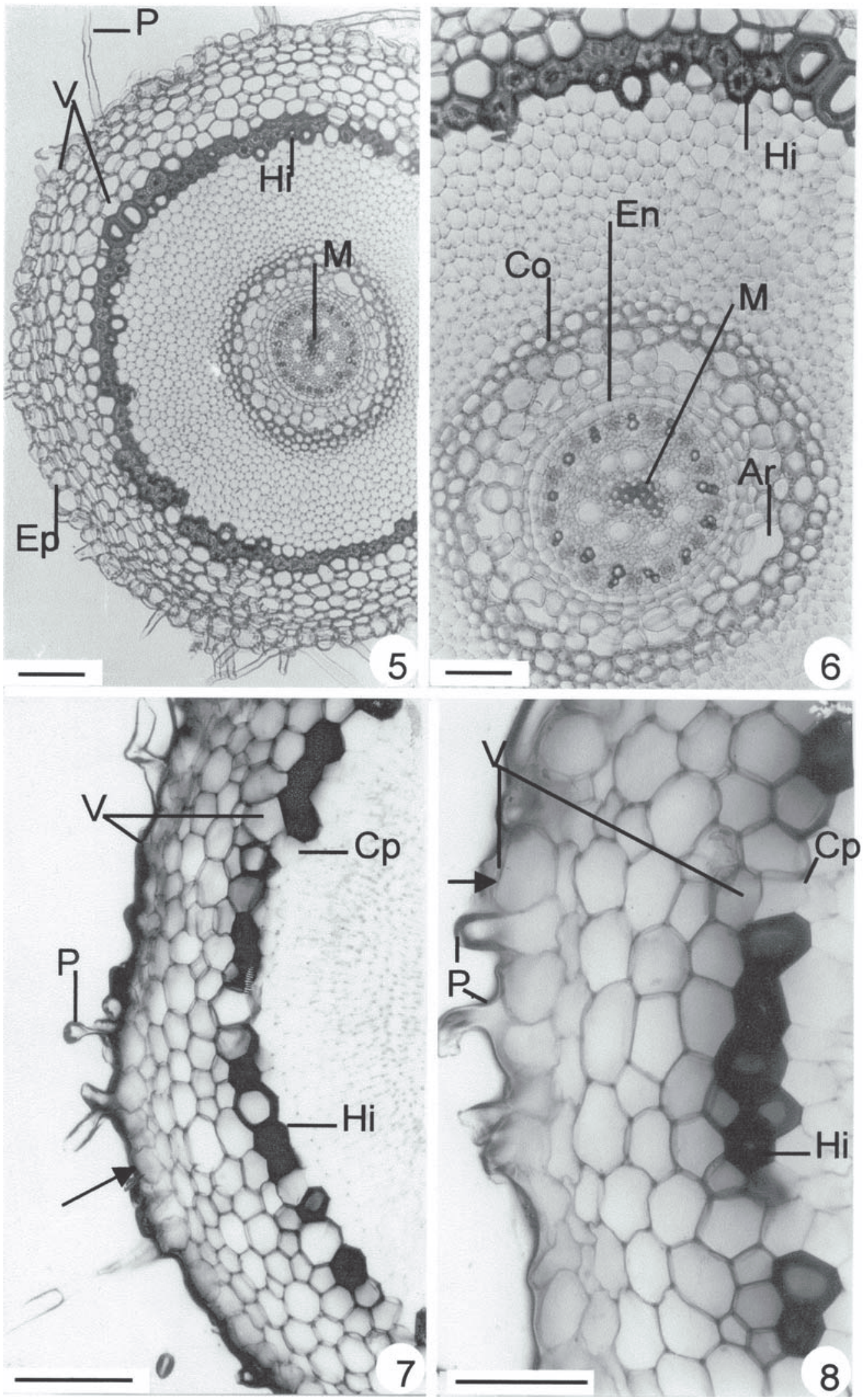

Figuras 5-8. Secções transversais da região apical da raiz adventícia de Encholirium heloisae (R.C. Forzza 102). As setas das figuras 7 e 8 indicam células do velame ainda estratificadas. Nesta fase, a hipoderme (Hi) apresenta-se unisseriada e a endoderme com estrias de Caspary. $\mathrm{Ar}=$ espaços aéreos, $\mathrm{Co}=$ tecido colenquimatoso, $\mathrm{Cp}=$ células de passagem, Ep = epivelame, $\mathrm{M}=$ medula, $\mathrm{P}=$ pêlo radicular. Escalas $=250 \mu \mathrm{m}$ (fig. 5); $100 \mu \mathrm{m}$ (fig. 6,7);50 $\mu \mathrm{m}$ (fig. 8). 

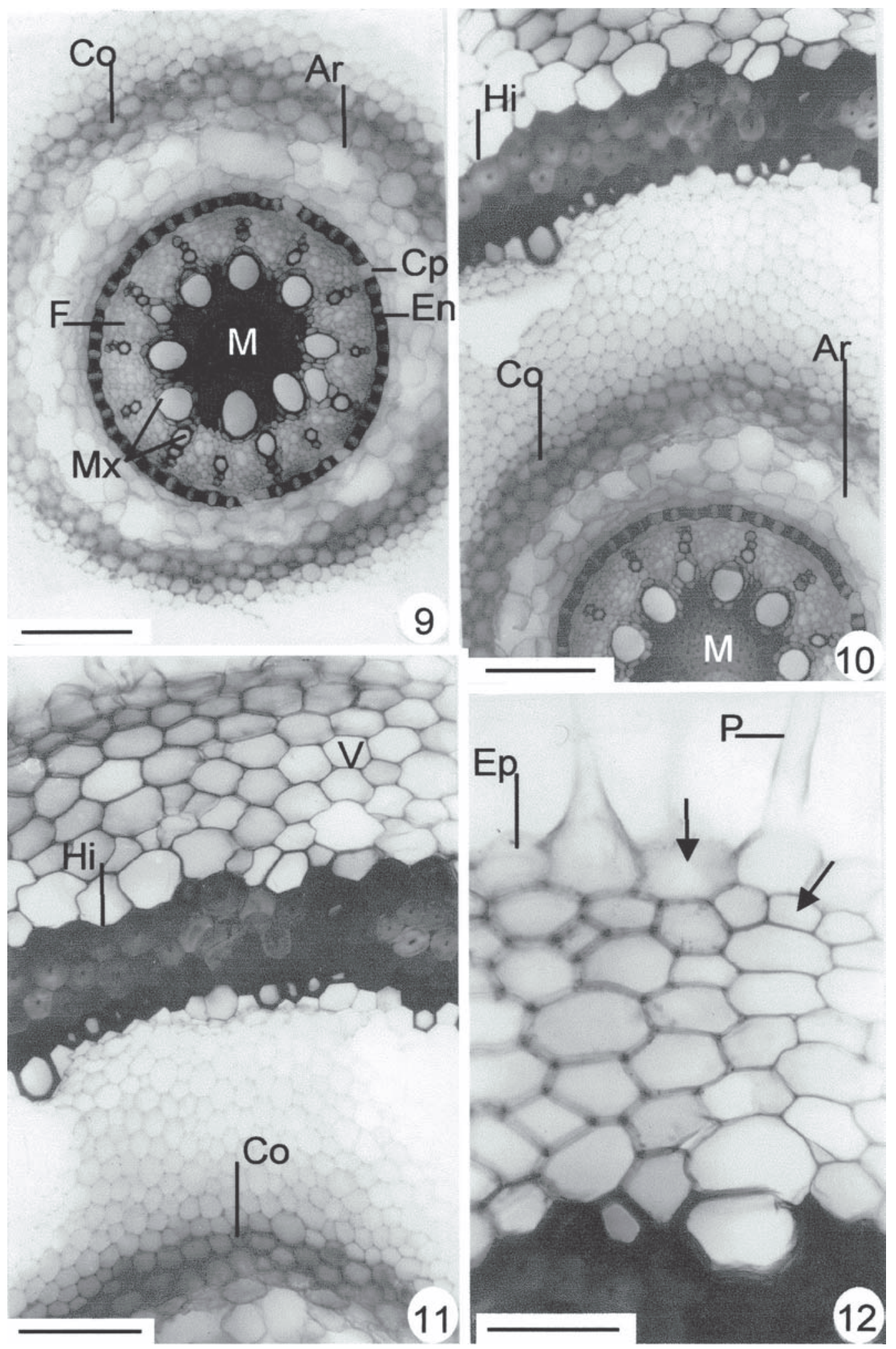

Figuras 9-12. Secções transversais da região mediana da raiz adventícia de Encholirium heloisae (R.C. Forzza 102). As setas da figura 12 indicam células ainda estratificadas. A endoderme (En) apresenta espessamento em $\mathrm{O}$, com estrias só nas células de passagem $(\mathrm{Cp})$. A partir da hipoderme, observa-se uma progressiva esclerificação do córtex. $\mathrm{Ar}=$ espaços aéreos, $\mathrm{Co}=$ tecido colenquimatoso, $\mathrm{Ep}=$ epivelame, $\mathrm{Hi}$ = hipoderme, $\mathrm{F}=$ floema, $\mathrm{M}=$ medula, $\mathrm{Mx}=$ metaxilema, $\mathrm{P}=$ pêlo radicular, $\mathrm{V}=$ velame. Escalas $=100 \mu \mathrm{m}$ (fig. 9-11); $50 \mu \mathrm{m}$ (fig. 12). 

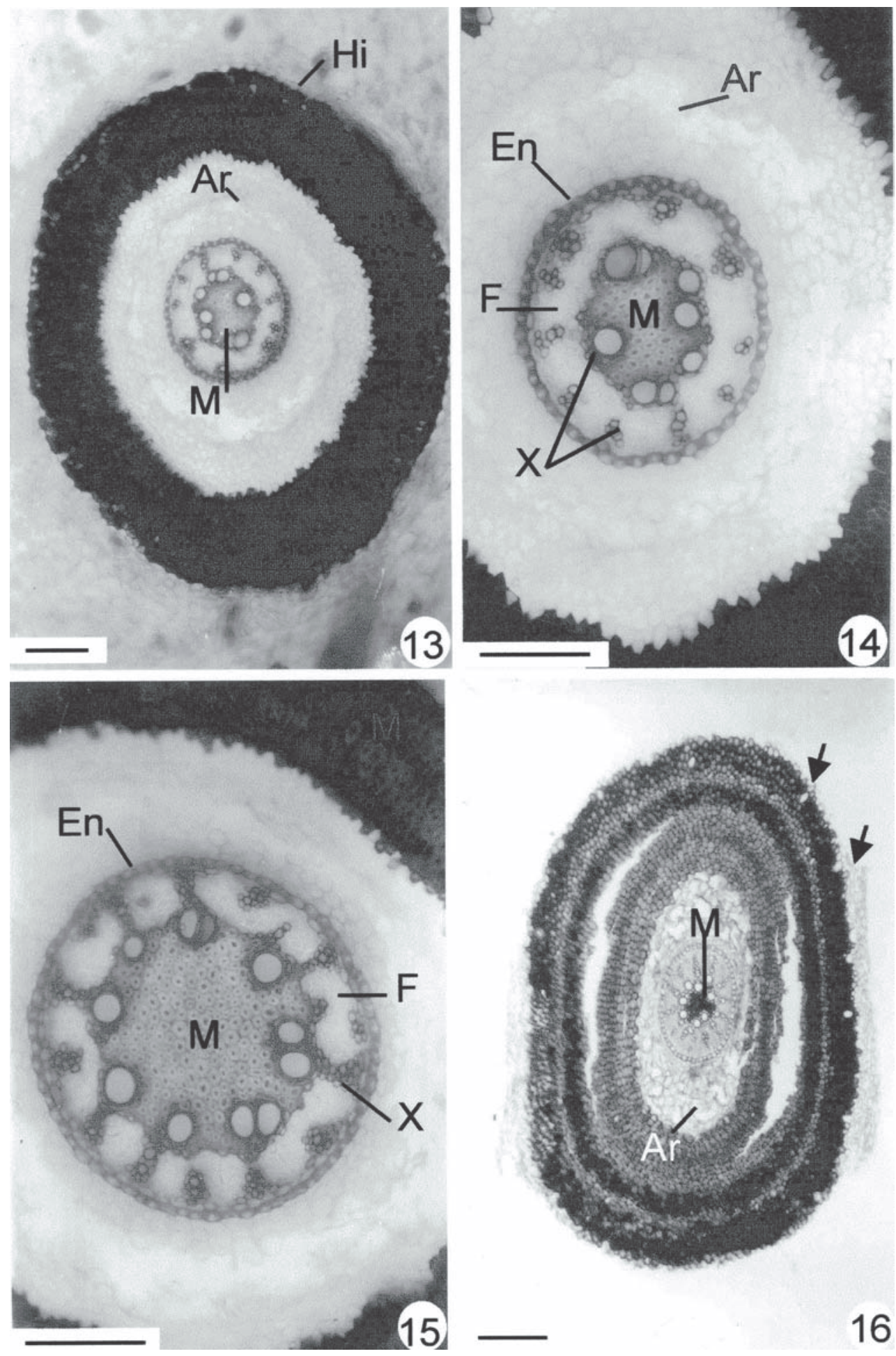

Figuras 13-15. Secções transversais da raiz adventícia intracortical de Dyckia macedoi (R.C. Forzza 100), na região basal do caule. Nota-se uma maior esclerificação das células do córtex à partir da hipoderme (Hi), a endoderme (En) com reforço em $\mathrm{O}$ (figuras 14-16) e o parênquima medular (M) totalmente espessado. Chama a atenção nas figuras 13-15 a quantidade de células de floema (Fl). Figura 16. Secção transversal de uma raiz onde verifica-se que o velame já se destacou (setas). Ar = espaços aéreos, $\mathrm{F}=$ floema, $\mathrm{X}=$ xilema. Escalas = $100 \mu \mathrm{m}$ (fig. 13-15); $50 \mu \mathrm{m}$ (fig. 16). 

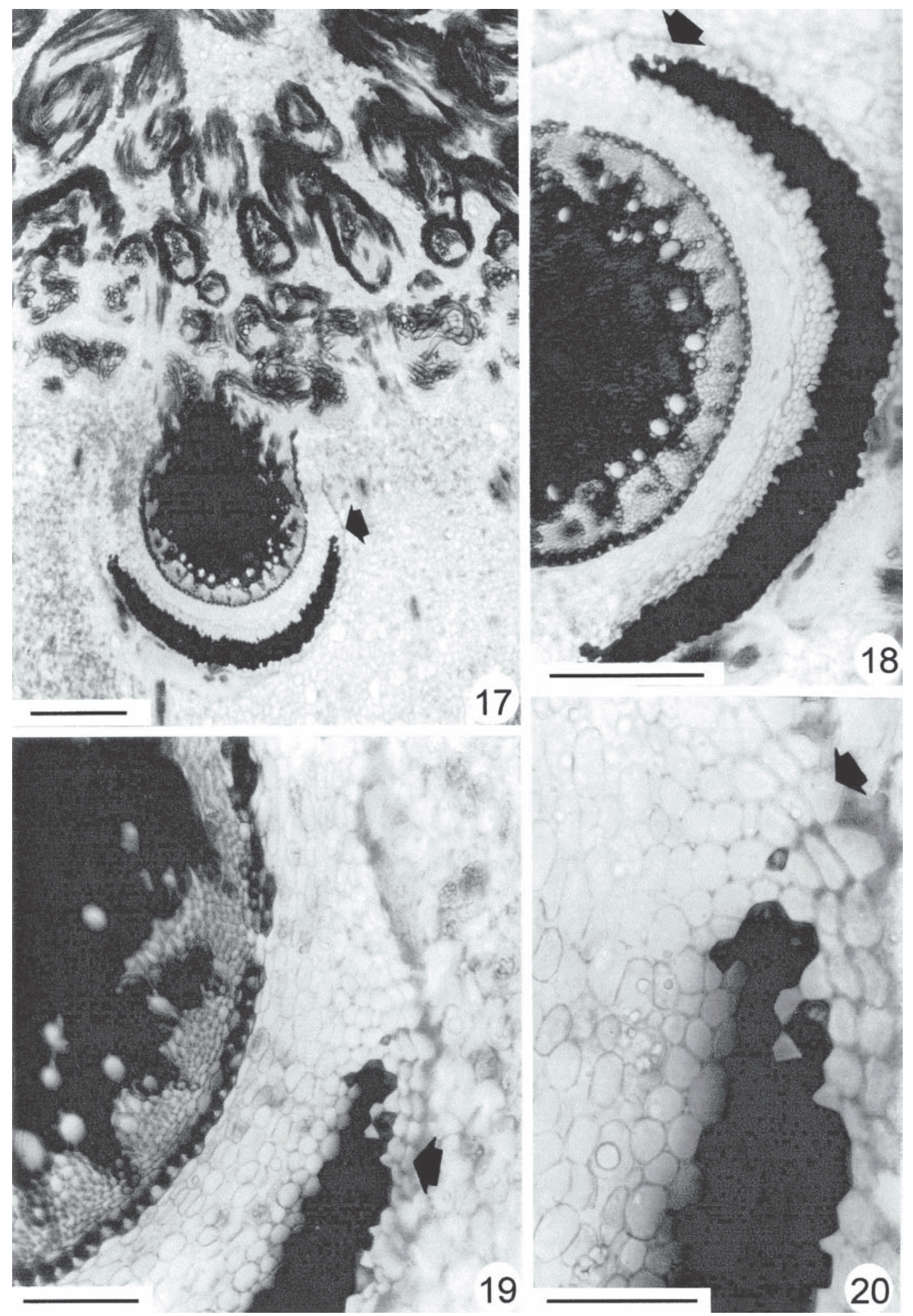

Figuras 17-20. Secção transversal da região basal do caule de Dyckia macedoi (R.C. Forzza 100) em várias magnitudes. Note-se a saída de uma raiz que se encontra no córtex. As setas das figuras 17-20 indicam células epidérmicas em divisão para originar o velame. Escalas $=100 \mu \mathrm{m}$ (fig. 17); $73 \mu \mathrm{m}$ (fig. 18); $50 \mu \mathrm{m}$ (fig. 19); $25 \mu \mathrm{m}$ (fig. 20). 
córtex caulinar (como é o caso das raízes representadas nas figuras 13-15), o parênquima cortical já se apresenta com várias camadas de células de paredes espessadas, além da própria hipoderme.

As figuras 1-4 correspondem à raízes de uma planta jovem obtida de germinação da semente. As setas nas figuras 3 e 4 indicam as séries resultantes de divisões de células protodérmicas, para constituir o velame.

\section{Discussão}

Analisando os tecidos da raiz de fora para dentro, verifica-se uma região constituída por células com características parenquimáticas com paredes delgadas, apresentando uma estratificação, tanto nas raízes adventícias de plantas adultas como na raiz primária de plantas jovens. Essa estratificação significa que essas células se originaram de uma mesma inicial, constituindo uma epiderme pluriestratificada ou velame.

A presença de velame, relatada em Velloziaceae por Menezes \& Giulietti (1986), foi posteriormente confirmada por Porembski \& Bartholott (1995), sendo estas as únicas observações da ocorrência de velame na superordem Bromeliiflorae. No entanto, nenhum dos autores consultados até o momento (Esau 1966, Tomlinson 1969, Cutter 1969 e 1971, Fahn 1974, Mauseth 1988, Benzing 1990, dentre outros), assumem a possibilidade da ocorrência de um velame nas raízes de Bromeliaceae. O que já foi descrito como epiderme e exoderme nas raízes de espécies da família Bromeliaceae, na realidade, corresponde ao que se verificou tratar-se de um verdadeiro velame. Segundo diversos autores (Engard 1944, Dycus \& Knudson 1957, Esau 1966, Cutter 1969 e 1971, Fahn 1974, Mauseth 1988), o velame ocorre em raízes de plantas terrestres e epífitas de Orchidaceae e Araceae e consiste de uma a várias camadas de células, que se originam de divisões periclinais das iniciais da protoderme. A camada mais externa, às vezes, se diferencia das camadas internas no padrão de desenvolvimento e é formada por células, geralmente, menores que as células das demais camadas. Devido a essas distinções, Sanford \& Adalawo (1973) sugeriram o termo epivelame para esta camada externa. Sob condições ambientais apropriadas, a camada externa pode desenvolver pêlos radiculares (Engard 1944), como o observado nas espécies de Dyckia e Encholirium estudadas (figuras 1-2, 5, 7, 8, 12) e essa presença de pêlos em raízes de orquídeas também foi observada por Dycus \& Knudson (1957) e Benzing et al. (1982). Sanford \& Adalawo (1973) observaram a presença de pêlos em orquídeas epífitas de coqueiros. Entretanto, não foi observada a presença desses pêlos em raízes de uma espécie rupícula de Pleurothallis rupestris Lindl. (Orchidaceae) por Scatena \& Nunes (1996).

O velame das orquídeas funciona como uma esponja (a entrada de água é puramente passiva), permitindo que a raiz mobilize uma reserva temporária, mas altamente acessível, de água e sais minerais (Benzing et al. 1982). Uma vez em contato com esses fluidos, os mesmos penetram no velame por capilaridade (Esau 1966, Benzing 1990). Benzing atribui ao velame uma função de proteção, quando ele se encontra vazio, isto é, com células cheias de ar. Por outro lado, Dycus \& Knudson (1957) verificaram que na região apical da raiz, onde o velame apresenta células vivas, ocorre absorção de água e nutrientes. Mas como essa região é reduzida, sua capacidade de absorção é insignificante. Nas espécies de Dyckia e Encholirium estudadas, a absorção ocorre, provavelmente, na região apical, onde o velame apresenta pêlos absorventes, onde ainda não ocorreu o espessamento das células corticais e onde a endoderme ainda se apresenta com estrias de Caspary.

Além do velame, a hipoderme (por outros autores denominada exoderme) pode diminuir a transpiração da raiz, como foi observado em orquídeas por Sanford \& Adalawo (1973), Benzing et al. (1982), Benzing et al. (1983).

Segundo a maioria dos autores (Engard 1944, Esau 1966, Cutter 1969, 1971, Fahn 1974, Rudall 1987), a exoderme é uma camada unisseriada que posiciona o limite externo do tecido cortical, ou seja, é a camada mais externa do córtex, portanto, origina-se do meristema fundamental. Outros autores chamam a exoderme de hipoderme (Barnabas 1996, Seago et al.1999 a, b), denominação esta usada, mais comumente, apenas para folha e caule, também adotada neste trabalho. Nas espécies de Dyckia e Encholirium aqui analisadas, a primeira camada de células abaixo da epiderme é, realmente, uma hipoderme, pois, além de se encontrar abaixo da epiderme, constitui uma camada de células que, na região pilífera apresenta-se unisseriada, formada por células de paredes espessadas intercaladas com células de paredes não espessadas, as células de passagem. Internamente à hipoderme, na região do ápice radicular, ocorre um córtex totalmente parenquimático. Em outros níveis da raiz, se observa um espessamento progressivo das células corticais até o ponto em que apenas o parênquima com espaços aéreos permanece com células de paredes delgadas. Devido a esse espessamento, torna-se difícil distinguir a hipoderme. Por essa razão, o tecido aqui denominado de velame foi denominado de córtex externo por outros autores (Meyer 
1940, Tomlinson 1969, Smith \& Downs 1974).

Estudando Aechmea fasciata (Lindley)Baker, Meyer (1940) chamou de exoderme o que constitui o velame, e de rizoderme, o que representa a primeira camada de células, isto é, o epivelame. A camada mais externa dos tecidos por ele chamada de "córtex externo" ("Außerinde", literalmente seria casca externa) é a hipoderme e as camadas internamente localizadas são células do córtex que se espessaram. Da mesma maneira, Tomlinson (1969) referindo-se à Vriesia swartzii (Baker) Mez e Smith \& Downs (1974) referindo-se à Billbergia sanderiana E. Morren também chamaram de exoderme o que, na verdade, corresponde ao velame e de córtex externo à hipoderme e as demais células do córtex que se espessaram. $\mathrm{Na}$ primeira vez que Smith \& Downs (1974) mencionaram a epiderme, o fizeram referindo-se apenas ao epivelame, colocando as demais camadas dessa epiderme pluriestratificada como parte do córtex, o que representa um equívoco, uma vez que esses tecidos têm origem de meristemas diferentes, portanto, são dois tecidos diferentes.

Para o parênquima com espaços aéreos, como se vê nas espécies de Dyckia e Encholirium analisadas, Meyer (1940) admitiu a função de transporte de água por capilaridade através dos espaços. Nenhum autor se referiu à presença de células colenquimatosas, como ocorre nas espécies do presente trabalho.

Excluindo a planta jovem, cuja raiz primária apresenta metaxilema no interior, as demais raízes, por serem adventícias, possuem medula, que se encontra lignificada desde regiões bem jovens, próximas ao ápice, até a base da raiz. Tomlinson (1969) observou a rara presença de vasos medulares isolados do cilindro vascular, em espécies de Hohenbergia e Pitcairnia. Harms (1930 apud Smith \& Downs 1974) observou uma redução dos tecidos vasculares nas espécies epífitas, considerando que tal redução se deve ao fato das raízes dessas espécies apresentarem apenas função de fixação. Em diferentes alturas da raiz, ainda intracortical, podese observar o aparecimento da conexão de cordões isolados de protoxilema com o metaxilema correspondente, possivelmente por diferenciação de células de um parênquima potencialmente vascular.

De acordo com Tomlinson (1969), as raízes intracaulinares diferem das raízes extracaulinares pela ausência de pêlos radiculares nas primeiras, também observado nas espécies de Dyckia e Encholirium aqui analisadas. Esse mesmo autor afirma, ainda, que as raízes intracorticais não apresentam exoderme e espaços aéreos, mas essas características não corroboram com o que foi verificado nas espécies de Dyckia e Encholirium, pois, o autor chama de exoderme o velame e este é que, em geral, está ausente nas raízes intracorticais. Neste trabalho, no entanto, foi verificado que a epiderme se divide, justamente, numa raiz intracortical, onde se observou a formação de uma epiderme uni, bi e trisseriada.

Agradecimentos - À Coordenadoria de Aperfeiçoamento do Pessoal de Ensino Superior (CAPES), pela concessão da bolsa de Mestrado à primeira autora; à FAPESP, pelo auxílio concedido (Processo 1997/0493-2), que permitiu a finalização do trabalho; à Rafaela Campostrini Forzza e Profa. Dra. Maria das Graças Lapa Wanderley, pela identificação das espécies; à Rosani do Carmo de Oliveira Arruda, pela leitura crítica do manuscrito.

\section{Referências}

BARNABAS, A. D. 1996. Casparian band-like structures in the root hypodermis of some aquatic angiosperms. Aquatic Botany 55:217-225.

BENZING, D.H. 1973. The monocotyledons: their evolution and comparative biology. I. Mineral nutrition and related phenomena in Bromeliaceae and Orchidaceae. The Quarterly Review of Biology 48:277-290.

BENZING, D.H. 1976. Bromeliad trichomes: structure, function and ecological significance. Selbyana 1:330-348.

BENZING, D.H. 1990. Vascular epiphytes - general biology and related biota. Cambridge University Press, Cambridge.

BENZING, D.H. \& DAHLE, C.E. 1971. The vegetative morphology, habitat preference and water balance mechanisms of the bromeliad Tillandsia ionantha Planch. The American Midland Naturalist 85:11-21.

BENZING, D.H., FRIEDMAN, W.E., PETERSON, G. \& RENFROW, A. 1983. Shootlesness, velamentous roots, and the pre-eminence of Orchidaceae in the epiphytic biotope. American Journal of Botany 70:121-133.

BENZING, D. H., HENDERSON, K., KESSEL B. \& SULAK, J. 1976. The absorptive capacities of bromeliad trichomes. American Journal of Botany 63:1009-1014.

BENZING, D.H., OTT, D.W. \& FRIEDMAN, W.E. 1982. Roots of Sobralia macrantha (Orchidaceae): structure and function of the velamen-exodermis complex. American Journal of Botany 69:608-614.

BENZING, D.H., SEEMAN, J. \& RENFROW, A. 1978. The foliar epidermis in Tillandsioideae (Bromeliaceae) and its role in habitat selection. American Journal of Botany 65: 359-365.

CRONQUIST, A. 1981. An integrated system of classification of flowering plants. Columbia University Press, New York.

CUTTER, E.G. 1969. Plant anatomy: experiment and interpretation. Part I. Edward Arnold, London. 
CUTTER, E.G. 1971. Plant anatomy: experiment and interpretation. Part II. Edward Arnold, London.

DAHLGREN, R.M. T., CLIFFORD, H.T. \& YEO, P.F. 1985. The families of the monocotyledons structure, evolution and taxonomy. Springer-Verlag, New York.

DYCUS, A.M. \& KNUDSON, L. 1957. The role of the velamen of the aerial roots of orchids. Botanical Gazette 119:78-87.

ENGARD, C.J. 1944. Morphological identity of the velamen and exodermis in orchids. Botanical Gazette 105:457-462.

ESAU, K. 1966. Anatomy of seed plants. $2^{\text {nd }}$ ed. John Wiley \& Sons, New York.

FAHN, A. 1974. Plant Anatomy. $2^{\text {nd }}$ ed. Pergamon Press, Oxford.

GILMARTIN, A.J. 1972. Trichomes of some equadorian Bromeliaceae. Morris Arboretum Bulletim 23:19-23.

GIULIETTI, A.M., MENEZES, N.L., PIRANI, J.R., MEGURO, M. \& WANDERLEY, M.G.L. 1987. Flora da Serra do Cipó, Minas Gerais: caracterização e lista das espécies. Boletim de Botânica, Universidade de São Paulo 9:1-151.

JOHANSEN, D.A. 1940. Plant microtechnique. McGraw-Hill Book Co., New York.

JOLY, A.B. 1970. Conheça a vegetação brasileira. EDUSP e Polígono. São Paulo.

KÖPPEN, W. 1931. Climatologia. Fondo de Cultura Economica, Buenos Aires.

KRAUS, J.E., SOUSA, H.C., RESENDE, M.H. CASTRO, N.M., VECCHI, C. \& LUQUE, R. 1998. Astra blue and basic fuchsin double staining of plant material. Biotechnic \& Histochemistry 73:235-243.

MAUSETH, J.D. 1988. Plant anatomy. The Benjamin Cummings Publishing Company, Inc. California.

MENEZES, N.L. \& GIULIETTI, A.M. 1986. Campos rupestres paraíso botânico na Serra do Cipó. Ciência Hoje 5:38-44.

MEYER, L. 1940. Zur anatomie und entwicklungsgeschichte der Bromeliaceenwurzeln. Planta 31:492-522.

PITTENDRIGH, C. S. 1948. The bromeliad-anopheles-malaria complex in Trinidad. I-The bromeliad flora. Evolution 2: 58-89.
POREMBSKI, S. \& BARTHLOTT, W. 1995. On the ocurrence of a velamen radicum in Cyperaceae and Velloziaceae. Nordic Journal of Botany 15:625-629.

REITZ, R. 1983. Bromeliáceas e a malária - bromélia endêmica. In Flora Ilustrada Catarinense parte 1 fascículo Bromélia: $1-58$.

RUDALL, P. 1987. Anatomy of flowering plants. An introduction to structure and development. Royal Botanic Gardens, Kew.

SANFORD, W.W. \& ADALAWO, I. 1973. Velamen and exodermis characters of West African epiphytic orchids in relation to taxonomic grouping and habitat tolerance. Botanical Journal of the Linnean Society 66:307-321.

SASS, J.E. 1951. Botanical microtechnique. 3ed. State Press, Iowa.

SCATENA, V.L. \& NUNES, A.C. 1996. Anatomia de Pleurothallis rupestris Lindl. (Orchidaceae) dos campos rupestres do Brasil. Boletim de Botânica, Universidade de São Paulo 15:35-43.

SEAGO, J. L., PETERSON, C.A. \& ENSTONE, D.E. 1999. Cortical ontogeny in roots of the aquatic plant Hydrocharis morsus-ranae L. Canadian Journal of Botany 77:113-121.

SEAGO, J.L., PETERSON, C.A., ENSTONE, D.E. \& SCHOLEY, C.A. 1999. Development of the endodermis and hypodermis of Typha glauca Godr. and Typha angustifolia L. roots. Canadian Journal of Botany 77: 122-134.

SMITH, L.B. \& DOWNS, R.J. 1974. Pticairnioideae. Flora Neotropica. (monograph 14 part 1). Hafner Press, New York.

TOMLINSON, P.B. 1969. Commelinales-Zingiberales. In Anatomy of the monocotyledons (C.R. Metcalfe, ed.). Clarendon Press, Oxford. v.3. 